$\underline{\xi}=-m$

\title{
Potential therapeutic effect of turmeric (Curcuma longa) against adverse effects of penconazole fungicide to white rats
}

\author{
Mona A. Abdel Rasoul *, Gehan I. Kh. Marei \\ Plant Protection Department, Faculty of Agriculture, Damanhour University, Damanhour, Albeheira, 22516 \\ *Corresponding author E-mail: mona.abdelnaby@agr.dmu.edu.eg
}

\begin{abstract}
This study aimed to investigate the prophylactic effect of turmeric (Curcuma longa) Rhizome Ethanolic extract (CLRE) at $250 \mathrm{mg} / \mathrm{kg}$ as antioxidant effects against penconazole induced sub-acute toxicity. Hepatic, renal and testicular pathological changes caused by oxidative damage induced by penconazole in rats were biochemically and histologically evaluated. Male rats were treated with penconazole, via oral route, at doses of $0.5 \mathrm{mg} / \mathrm{kg}$ body weight (b.w.; acute reference dose, ARfD), $25 \mathrm{mg} / \mathrm{kg}$ b.w. (no observed adverse effects level, NOAEL) and $100 \mathrm{mg} / \mathrm{kg}$ b.w. (1/20 lethal dose $\left.\left[\mathrm{LD}_{50}\right]\right)$ for 28 consecutive days. Penconazole treatments had significant $(p<0.05)$ and gradual reductions in body and relative testicular weight accompanied by significant elevation in the relative liver and kidney weights. Significant increase serum aspartate aminotransferase (AST), alanine aminotransferase (ALT), alkaline phosphatase (ALP), lactate dhydrogenase (LDH), gamma-glutamyl transferase (GGT), creatinine (Cre), uric acid and blood glucose was observed due to penconazole treatments. However, total protein and testosterone hormone were significantly decreased. Exposure to penconazole caused increase in lipid peroxidation (LPO) and decreased of liver and kidney antioxidant enzymes activity as catalase (CAT), superoxide dismutase (SOD) and glutathione peroxidase (GPx). Histopathological studies confirmed the ameliorative beneficial effects of turmeric biochemical parameters. On the basis of this study, the use of tumeric rhizomes as a functional food or as a nutraceutical product could be a useful approach to protect individuals who are regularly exposed to penconazole.
\end{abstract}

Keywords: Antioxidant; Curcuma Longa; Histological Studies; Oxidative Damage Penconazole; Therapeutic Effect.

\section{Introduction}

Use of fungicides in agriculture and garden caused toxic effects, which vary enormously in their potential. Fungicides can lead to acute or chronic poisoning in animals. Some livestock poisoning cases result from accidental overdosing or careless use of fungicide in animal's treatment. Currently and undoubtedly, fungicides will continue to be widely used in agriculture. Therefore, more attention should be carefully paid to use fungicides in agriculture. Azole fungicides show a broad antifungal activity for use in agriculture due to their preventive and curative properties to plant growth and therapeutics of human and veterinary (Zarn et al., 2003).

Azole fungicides are used on a wide variety of crops. Azoles fungicides can directly applied as canopy foliar and/or seed treatment and their antifungal activities contact and systemic. According to their chemical structure, Azoles are grouped into either class of imidazoles or triazoles. Penconazole (1-(2-(2,4-dichlorophenyl)pentyl)-1H-1,2,4-triazole), is asystemic triazole fungicide and it santifungal activity based on inhibition of lanosterol-14 $\alpha$ demethylase(CYP51) (Yoshida, 1988; Podust et al., 2001), which are phylogenetically widely distributed in mycobacteria, fungi, plants, animals and humans and highly conserved cytochrome P450 monooxygenase (McLean et al. 2002; Lepesheva et al., 2003). Azole compounds are rather lipophilic and penetrate to the cytochrome P450 enzymes within the endoplasmatic reticulum. This lipophilic character partially is responsible for toxicological profile. Inhibition of non-target cytochrome P450 enzymes leads to toxicologically relevant changes in the liver and endocrine sys- tem (Zarn et al., 2003). Furthermore, enzymes catalyzing metabolism of xenobiotics develops liver tumors in animal. This has been reported for e.g. cyproconazole, epoxiconazole and tebuconazole and Propiconazole (Zarn et al., 2003; Marquardt Schafer, 2004; Sun et al., 2005)

As a result of intensive application of penconazole in agriculture, residues can remain on treated crops after harvest and can consequently induce toxicological effects on the consumer. Indeed, penconazole exposure induces testicular dysfunction in male albino rats when administered at doses 50 and $100 \mathrm{mg} / \mathrm{kg}$ body weight (El-Sharkawy\&El-Nisr, 2013). Hepatotoxicity induced by penconazole at a dose of $67 \mathrm{mg} / \mathrm{kg}$ b.w. increased malondialdehyde, hydrogen peroxide, and advanced oxidation protein product levels (Chaabane et al., 2015).

Turmeric is a perennial herb derived from the rhizomes of $\mathrm{Curcu}$ ma longa, which is a member of ginger family (Zingiberaceae). Turmeric rhizomes contain approximately $2 \%$ volatile oils mainly consist of alpha and $B$-turmerone and monoterpenes, $5 \%$ curcuminoids, mainly include curcumin, demethoxycurcumin, bisdemethoxycurcumin and dihydrocurcumin as well as turmeric rhizomes contain minerals, carotene and vitamin C (Heath, 2004). Curcumin the principal curcuminoid found in turmeric and generally is used as a spice, pigment and for medicinal purposes. Curcumin may have anti-inflammatory and anticancer activities to prevent and treat the disease. (Kodjio et al., 2016) studied revealed that aqueous extract from Curcuma longa rhizomes has antityphoid and antioxidant activities. Based on the previous review, more attention should be paid to the protective effects of natural antioxidants against chemically induced toxicities. Therefore, the goal of the current study was to determine the effect of sub-acute 
penconazole exposure in the liver, kidney and testes male rats and reducing the harmful effect of penconazole by using antioxidant as Curcuma longa Linn ethanolic extract.

\section{Materials and methods}

\subsection{Chemicals}

A commercial formulation containing $100 \mathrm{~g} / \mathrm{L}$ penconazole was used (Topaz, Syngenta, Bale, and Suisse). The oral median lethal dose $\left(\mathrm{LD}_{50}\right)$ of penconazole in rat is $2,000 \mathrm{mg}$ according to FAO/WHO (1991). All other chemicals were purchased from Biodiagnostics Co., Dokki, Giza, Egypt. Other reagents used were of analytical grade.

\subsection{Preparation of Curcuma longa linn ethanolic extract}

Turmeric (Curcuma longa) rhizomes were purchased from the company of Agricultural Seeds, Herbs and Medicinal Plants, Cairo, Egypt. The dried rhizomes of turmeric were 'weighed and soaked in $95 \%$ ethanol at a ratio of 1:10 plant: ethanol and left for 3 days under shaking and stirring at $25^{\circ} \mathrm{C}$. The mixture was filtered and the resulting liquid was concentrated under low pressure at $45^{\circ} \mathrm{C}$ in rotary evaporator to yield a dark gummy-yellow extract $(6.4 \%, \mathrm{w} / \mathrm{w})$. The concentrated extract was kept in the incubator at $45^{\circ} \mathrm{C}$ for 3 days to evaporate the ethanol residue. Extracts were dissolved in corn oil before being orally feed to animals in concentrations of $250 \mathrm{mg} / \mathrm{kg}$ body weight.

\subsection{Determination of total phenolics}

Total Phenol content (TPC) of Curcuma longa rhizome ethanolic extract (CLRE) was determined by the Folin Denis calorimetric method using Folin-Ciocalteau reagent (Merck, Darmstadt, Germany) in Gallic acid equivalent (mg GAE/extract)( Zhang et al., 2006). Curcuma longa rhizome ethanolic extract $(1 \mathrm{mg})$ was first dissolved in $1 \mathrm{ml}$ dimethyl sulfoxide (DMSO). Thereafter, $20 \mu \mathrm{L}$ of the extract was added to $100 \mu \mathrm{L}$ of Folin-Ciocalteau reagent and incubated in the dark for $3 \mathrm{~min}$. Hundred $\mu \mathrm{L}$ of sodium carbonate solution $(1 \mathrm{~g} / 10 \mathrm{~mL})$ was added through the mixture. The final mixture was kept in the dark for $1 \mathrm{~h}$ and its absorbance at wavelength $750 \mathrm{~nm}$ using Jenway 6305 UV/VIS spectrophotometer (Shimadzu, Japan) was measured. The procedure repeated three times. Linear standard curves were produced by serial dilution of Gallic acid (1 mg/mL DMSO) and the absorbance was measured at wavelength $750 \mathrm{~nm}$ using the same aforementioned spectrophotometer. Result, clearly, showed that turmeric had the total phenolic content of $74.81 \mathrm{mg}$ GAE/100 g extract.

\subsection{Animals and experimental design}

Healthy male Wister rats weighing $125 \pm 3 \mathrm{~g}$ were obtained from the animal house, Faculty of Medicine, Alexandria University, Egypt. The local committee approved the design of the experiments and the protocol conforms to the guidelines of the National Institutes of Health (NIH). During the whole experimental period, animals were fed with a balanced commercial diet and water ad libitum. Animals maintained in clean plastic cages in the laboratory animal room $\left(23 \pm 2^{\circ} \mathrm{C}\right)$ and daily dark/light cycle $12 / 12 \mathrm{hrs}$ The rats were acclimatized of oral gavages for 28 consecutive days. After acclimatization, the rats were divided into 8 groups, each group of six rats and were maintained as follows:

Group 1: Served as a control and were given corn oil $(0.5 \mathrm{ml} / \mathrm{rat})$. Group II: given Curcuma longa rhizomes ethanolic extract (CLRE) in corn oil at a dose of $250 \mathrm{mg} / \mathrm{kg}$ body weight daily.

Group III: Given penconazole in corn oil at a dose of $0.5 \mathrm{mg} / \mathrm{kg}$ b.w. daily (acute reference dose, ARfD, EFSA, 2008).

Group IV: Given penconazole ( $25 \mathrm{mg} / \mathrm{kgb} . w$. daily (no observed adverse effects level, NOAEL, Basler et al.,1984; ECHA, 2012).
Group V: Treated with penconazole at a dose of $100 \mathrm{mg} / \mathrm{kg}$ b.w. $\left(1 / 20 \mathrm{LD}_{50}\right)$.

Group VI, VII and VIII: were the same doses of penconazole as in groups III, IV and V, respectively in combination with the Curcuma longa rhizomes extract. During the experimental duration, body weights were recorded and the doses modulated according to weekly body weight gain.

The surviving rats after treatment, in each group, were subjected for 2 days under light diethyl ether anesthesia and the liver, kidney and testes were immediately isolated, cleaned and weighed for biochemical investigation. Liver, kidney and testes were cut into small pieces and kept in $10 \%$ formalin solution for histological studies. Specimens from liver, kidney and testis were washed with saline solution, weighed, cut into small pieces, homogenized in $10 \%$ (w/v) ice cold $100 \mathrm{mM}$ phosphate buffer ( $\mathrm{pH} 7.4)$. Homogenates were centrifuged at $10.000 \mathrm{xg}$ at $4^{\circ} \mathrm{C}$ for $15 \mathrm{~min}$ and the supernatants were used for the measurements of antioxidant enzymes; CAT, SOD and GPx activity. Blood samples were collected from hepatic portal vein in clean sterile vials and left till clotting occurred for $30 \mathrm{~min}$ and centrifuged at $3000 \times \mathrm{g}$ for $15 \mathrm{~min}$ for biochemical analysis within one week. Serum samples were aliquot in eppendorf tubes to use each one for one time.

\subsection{Biochemical analysis}

\subsubsection{Enzymes activity}

The serum was used to determine the enzyme activities of aspartate aminotransferase (AST; EC 2.6.1.1) by a colorimetric method, alanine aminotransferase (ALT; EC 2.6.1.2) according to ( Reitman \& Frankel, 1957), Alkaline phosphatase (ALP; EC 3.1.3.1) as described by Young et al.(1975), $\gamma$-glutamyltransferase $(\gamma$-GT) as outlined by (Whitfield et al., 1973) and lactate dehydrogenase (LDH; EC 1.1.1.27) activity as indicator of necrotic cell death according to the method of (Vassault et al.,1983).

\subsubsection{Biochemical parameters}

Concentrations of glucose, total protein, creatinine and uric acid were measured according to the methods of (Tietz, 1995; Gornal et al.,1949; Larsen, 1972; Barham \&Trinder, 1972), orderly.

\subsubsection{Oxidative stress parameter}

Malondialdehyde, in serum, (MDA) as an indicator of lipid peroxidation was determined by a colorimetric method according to (Satoh et al.,1978).

\subsubsection{Antioxidant enzymes}

Liver and kidney Catalase (CAT; EC 1.11.1.6) were estimated according to the method described by (Aebi 1984) by assaying the hydrolysis of $\mathrm{H}_{2} \mathrm{O}_{2}$ and the resulting decrease in absorbance at 510 $\mathrm{nm}$ over a $3 \mathrm{~min}$ period at $25 \mathrm{C}^{\circ}$. The activity of CAT enzyme is expressed as $\mathrm{U} / \mathrm{mg}$ protein.

Superoxide dismutase activity (SOD; EC 1.15.1.1) was assayed by the procedure of (Nishikimi et al., 1972). The assay relies on the ability of the enzyme to inhibit phenazinemethosulphate mediated reaction of nitrobluetetrazollium dye.

Glutathione peroxidase (GPx) activity was measured using $\mathrm{H}_{2} \mathrm{O}_{2}$ as substrate according to the method described by (Paglia\& Valentine, 1987). The reaction was monitored indirectly as the oxidation rate of NADPH at wavelength $240 \mathrm{~nm}$ for $3 \mathrm{~min}$. Enzyme activity was expressed as $\mathrm{nmol} / \mathrm{mg}$ protein.

\subsubsection{Testosterone hormones}

Serum testosterone level was carried out according to the method reported by (Tietz, 1995) using International Immune Diagnostics Kits. 


\subsection{Histological studies}

Liver, kidney and testis samples, from all rats, were excised and fixed in $10 \%$ neutral formalin buffer for histological examination. The samples were processed using graded ethanol series and embedded in paraffin. Tissue sections $(5-\mu \mathrm{m}$ thick) were cut and stained with hematoxylin and eosin (H\&E). All sections were evaluated for the degree of liver, kidney and testis injury and assigned for severity of changes using scores on a scale of none (-), mild (+), moderate $(++)$ and severe $(+++)$ damages (Bancroft et al. 1996).

\subsection{Statistical analysis}

Appropriate analysis of variance on obtained results was achieved using one-way analysis of variance (Software SPSS version 9.2). Comparisons among different mean treatments were performed using Duncan's Multiple Range Test (SAS, 2013).

\section{Results}

During the study period, there were no clinical signs of toxicity in any group treatment.

\subsection{Body and organ weights}

Results of Table (1); indicated that, there were no significant differences in body and relative liver, kidney and testicular weights between Curcuma longa rhizomes extract and untreated rats due to the exposure during sub-acute toxicity. However, the treated groups with penconazole dosages $(0.5,25$, and $100 \mathrm{mg} / \mathrm{kg}$ b.w) exhibited significant $(\mathrm{p}<0.05)$ and gradual weigh loss in the body and relative testicular weights accompanied by significant increments in the relative liver and kidney weights. Unfortunately, when CLRE extract were administrated to penconazole treated groups, significant enhancements of all above-mentioned parameters were detected.

Table 1: Effect of Penconazole (Pen.) Treatments on Body and Relative Liver, Kidney and Testes Weights of Rats and the Ameliorative Role of C. Longa Rhizome Ethanolic Extract (CLRE).

\begin{tabular}{|c|c|c|c|c|c|c|}
\hline \multirow{3}{*}{ Treatment } & \multicolumn{3}{|c|}{ Body weight } & \multirow{2}{*}{ Relative liver } & \multirow{2}{*}{ Relative kidney } & \multirow{2}{*}{ Relative Testes } \\
\hline & Initial (g) & Final $(\mathrm{g})$ & $\%$ Change/week & & & \\
\hline & minal (g) & Final (g) & \% Cnange/weeк & \multicolumn{3}{|c|}{ (g/100g body weight) } \\
\hline Untreated Control & $124.17 \pm 0.87^{\mathrm{abc}}$ & $235.33 \pm 1.58^{\mathrm{a}}$ & $22.38 \pm 0.09^{\mathrm{a}}$ & $4.01 \pm 0.02 \mathrm{~d}^{\mathrm{e}}$ & $0.61 \pm 0.009^{f}$ & $1.29 \pm 0.011^{\mathrm{ab}}$ \\
\hline CLRE & $124.17 \pm .79^{\mathrm{abc}}$ & $233.50 \pm 1.18^{\mathrm{a}}$ & $22.02 \pm 0.10^{\mathrm{a}}$ & $3.99 \pm 0.04^{\mathrm{e}}$ & $0.61 \pm 0.006^{\mathrm{f}}$ & $1.312 \pm 0.011^{\mathrm{a}}$ \\
\hline Pen.0.5mg/kg & $126.33 \pm 0.67^{\mathrm{a}}$ & $229.0 \pm 1.46^{\mathrm{b}}$ & $20.32 \pm 0.30^{b}$ & $4.16 \pm .05^{\mathrm{c}}$ & $0.66 \pm 0.006^{\mathrm{de}}$ & $1.246 \pm 0.024^{c}$ \\
\hline Pen. $25 \mathrm{mg} / \mathrm{kg}$ & $125.00 \pm 0.36^{\mathrm{ab}}$ & $219.50 \pm 0.56^{\mathrm{c}}$ & $18.90 \pm 0.10^{\mathrm{c}}$ & $4.54 \pm .02^{\mathrm{b}}$ & $0.73 \pm 0.003^{\mathrm{c}}$ & $1.098 \pm 0.01^{\mathrm{d}}$ \\
\hline Pen. $100 \mathrm{mg} / \mathrm{kg}$ & $124.83 \pm 1.05^{\mathrm{abc}}$ & $201.17 \pm 2.12^{\mathrm{e}}$ & $15.28 \pm 0.09^{\mathrm{e}}$ & $5.28 \pm 0.07^{\mathrm{a}}$ & $0.94 \pm 0.012^{\mathrm{a}}$ & $0.91 \pm .0117^{\mathrm{e}}$ \\
\hline Pen. $0.5 \mathrm{mg} / \mathrm{kg}+$ CLRE & $125.00 \pm 0.97^{\mathrm{ab}}$ & $225.83 \pm 1.96^{\mathrm{b}}$ & $20.17 \pm 0.12^{b}$ & $4.11 \pm 0.02^{\mathrm{cd}}$ & $0.64 \pm 0.002^{\mathrm{e}}$ & $1.30 \pm 0.008^{\mathrm{a}}$ \\
\hline Pen $.25 \mathrm{mg} / \mathrm{kg}+$ CLRE & $122.50 \pm 0.72^{c}$ & $217.00 \pm 1.32^{\mathrm{c}}$ & $19.29 \pm 0.08^{\mathrm{c}}$ & $4.23 \pm 0.02^{\mathrm{c}}$ & $0.67 \pm 0.003^{\mathrm{d}}$ & $1.26 \pm 0.002^{\mathrm{bc}}$ \\
\hline Pen. $100 \mathrm{mg} / \mathrm{kg}+$ CLRE & $123.83 \pm 0.40^{\mathrm{bc}}$ & $210.00 \pm 1.06^{\mathrm{d}}$ & $17.39 \pm 0.09^{\mathrm{d}}$ & $4.54 \pm 0.02^{\mathrm{b}}$ & $0.77 \pm 0.005^{\mathrm{b}}$ & $1.09 \pm 0.005^{\mathrm{d}}$ \\
\hline
\end{tabular}

Each value is a mean of 6 rats \pm S.E.M; $a, b, c, d$ values are not sharing superscripts letters $(a, b, c, d)$ differ significantly at $p<0.05$; $\%$ of body weight change/week $=[($ final b .w t. - initial b .wt. $) /$ initial b .wt. $] /$ no of weeks X 100

\subsection{Biochemical measurements}

The oral administration of Curcuma longa rhizomes extract (CLRE) to normal rats did not reflect any changes in all biochemical tested parameters compared to the normal control (Tables 2, 3 \&4).

Data tabulated in Table (2) clarified that, after 28 days of penconazole administration at $0.5,25$, and $100 \mathrm{mg} / \mathrm{kg} \mathrm{b.w,} \mathrm{ALT}$, AST, ALP, $\gamma$-GT and LDH activities were significantly increased as compared with control. The increase in activity for each detrimental enzyme was more pronounced at the higher dose of penconazole $(100 \mathrm{mg} / \mathrm{kg}$ b.w.) than those of intermediate dose $(25$ $\mathrm{mg} / \mathrm{kg} \mathrm{b}$. w.) and the lower one $(0.5 \mathrm{mg} / \mathrm{kg} \mathrm{b}$. w).

In contrast, the treated rates with penconazole a t0.5, 25, and 100 $\mathrm{mg} / \mathrm{kg}$ b.w, significantly $(\mathrm{P}<0.05)$, decreased total protein in comparison with the untreated rates. On the other hand, increasing penconazole from 0.5 to 25 and furtherly to $100 \mathrm{mg} / \mathrm{kg}$ b.w., progressively and significantly, elevated serum glucose level in treated rates as compared with the control. However, co-administration of CLRE extract to the treated rats with penconazole induced a partial recovery in the above-mentioned parameters.

Fig. 1, represents the changes in both levels of serum creatinine and uric acid in various experimental groups. Penconazole treatment (irrespective of the concentration used), gradually and significantly, elevated serum creatinine and uric acid levels as compared to control group. The highest penconazole dose $(100 \mathrm{mg} / \mathrm{kg} \mathrm{b.w.)}$, the highest levels were the serum creatinine and uric acid. However, oral administration of CLRE extract to normal rats produced no changes in the cited above biochemical parameters when compared to the untreated control. Treatment with CLRE extract markedly restored activities to the normal levels.
Fig. 2, illustrated that, the penconazole treatments, statistically, lowered the testosterone hormone concentrations in serum $(\mathrm{p}<0.05)$ than the control. The lowest significant testosterone concentration was recorded with the high penconazole dose 100 $\mathrm{mg} / \mathrm{kg}$ b.w. $(2.89 \mathrm{ng} / \mathrm{ml})$. It was noticed that, administration of CLRE to penconazole treated groups caused pronounced increase in testosterone concentration compared to the control rats $(4.81$ $\mathrm{ng} / \mathrm{ml})$.

\subsection{Oxidative stress markers}

Treated groups with penconazole at $0.5,25$ and $100 \mathrm{mg} / \mathrm{kg}$ b.w. led to significant increments $(\mathrm{p}<0.05)$ over the control in lipid peroxidation of serum MDA levels by 33,36 , and $44 \%$, respectively. However, the combined treatments of penconazole at 0.5 , 25 and $100 \mathrm{mg} / \mathrm{kg}$ b.w. and CLRE extract reduced the augmentation of serum MDA levels to 7, 10 and 19\%, orderly (Fig. 3).The activities of CAT, SOD and GPx in liver and kidney under the effect of penconazole at different concentrations and their combination with CLRE extract are illustrated in Table (3). Penconazole treated rate groups accompanied with injury and extensive oxidative damage due to the significant reduction in the activities of CAT, SOD and GPx in liver and kidney as compared to the untreated group. However, the addition of CLRE extract to treatedpenconazole groups, significantly, increased antioxidant parameters; CAT, SOD and GPx activities in liver and kidney. On the other hand, treatment with CLRE extract alone did not reflect any significant alteration in SOD, GPx and CAT activity compared to control treatment. 
Table 2: Effect of $C$. longa rhizome ethanolic extract (CLRE) on the serum biochemical factors in penconazole (Pen.) induced male rats.

\begin{tabular}{|c|c|c|c|c|c|c|c|}
\hline Treatment & $\begin{array}{c}\text { Total protein } \\
\mathrm{g} / \mathrm{dl}\end{array}$ & $\begin{array}{c}\text { Glucose } \\
\mathrm{mg} / \mathrm{dl}\end{array}$ & $\begin{array}{l}\mathrm{AST} \\
\mathrm{U} / \mathrm{L}\end{array}$ & $\begin{array}{l}\text { ALT } \\
\mathrm{U} / \mathrm{L}\end{array}$ & $\begin{array}{l}\text { ALP } \\
\text { U/L }\end{array}$ & $\begin{array}{l}\text { GGT } \\
\text { U/L }\end{array}$ & $\begin{array}{l}\mathrm{LDH} \\
\mathrm{U} / \mathrm{L}\end{array}$ \\
\hline Untreated Control & $7.04 \pm 0.03^{\mathrm{a}}$ & $88.63 \pm 0.52^{f}$ & $37.56 \pm 0.25^{\mathrm{f}}$ & $43.06 \pm 0.54^{\mathrm{e}}$ & $134.66 \pm 0.58^{\mathrm{g}}$ & $10.26 \pm 0.23^{\mathrm{e}}$ & $157.85 \pm 1.00^{f}$ \\
\hline CLRE & $6.95 \pm 0.02^{\mathrm{a}}$ & $88.14 \pm 0.55^{\mathrm{f}}$ & $38.57 \pm 0.17^{\mathrm{ef}}$ & $44.39 \pm 0.24^{\mathrm{e}}$ & $135.08 \pm 0.68^{\mathrm{g}}$ & $10.37 \pm 0.18^{\mathrm{e}}$ & $158.33 \pm 1.14^{\mathrm{f}}$ \\
\hline Pen $.0 .5 \mathrm{mg} / \mathrm{kg}$ & $6.71 \pm 0.04^{\mathrm{b}}$ & $93.15 \pm 0.33^{\mathrm{d}}$ & $41.80 \pm 0.25^{\mathrm{d}}$ & $50.91 \pm 0.35^{\mathrm{d}}$ & $152.65 \pm 0.72^{\mathrm{e}}$ & $11.59 \pm 0.24^{\mathrm{d}}$ & $165.78 \pm 2.97^{\mathrm{d}}$ \\
\hline Pen. $25 \mathrm{mg} / \mathrm{kg}$ & $6.32 \pm 0.03^{c}$ & $106.44 \pm 0.33^{c}$ & $56.11 \pm 0.45^{\mathrm{d}}$ & $68.59 \pm 0.71^{\mathrm{c}}$ & $192.87 \pm 0.82^{c}$ & $14.80 \pm 0.15^{\mathrm{c}}$ & $188.77 \pm 2.54^{\mathrm{b}}$ \\
\hline Pen. $100 \mathrm{mg} / \mathrm{kg}$ & $5.76 \pm 0.04^{\mathrm{d}}$ & $125.38 \pm 0.59^{\mathrm{a}}$ & $85.99 \pm 0.83^{b}$ & $101.07 \pm 1.09^{\mathrm{a}}$ & $311.57 \pm 0.93^{\mathrm{a}}$ & $22.46 \pm 0.64^{\mathrm{a}}$ & $242.52 \pm 1.94^{\mathrm{a}}$ \\
\hline Pen. $0.5 \mathrm{mg} / \mathrm{kg}+$ CLRE & $6.95 \pm 0.04^{\mathrm{a}}$ & $90.43 \pm 0.39^{\mathrm{e}}$ & $38.97 \pm 0.20^{\mathrm{e}}$ & $44.52 \pm 0.39^{\mathrm{e}}$ & $141.36 \pm 0.59^{f}$ & $10.58 \pm 0.15^{\mathrm{e}}$ & $159.47 \pm 0.66^{\mathrm{ef}}$ \\
\hline Pen. $25 \mathrm{mg} / \mathrm{kg}+$ CLRE & $6.77 \pm 0.02^{b}$ & $93.82 \pm 0.25^{\mathrm{d}}$ & $42.29 \pm 0.24^{\mathrm{d}}$ & $50.21 \pm 0.57^{\mathrm{d}}$ & $155.94 \pm 0.64^{\mathrm{d}}$ & $11.78 \pm 0.30^{\mathrm{d}}$ & $164.65 \pm 2.75^{\mathrm{de}}$ \\
\hline
\end{tabular}

Each value is a mean of 6 rats \pm S.E.M; $a, b, c, d$ values are not sharing superscripts letters $(a, b, c, d)$ differ significantly at $p<0.05$.
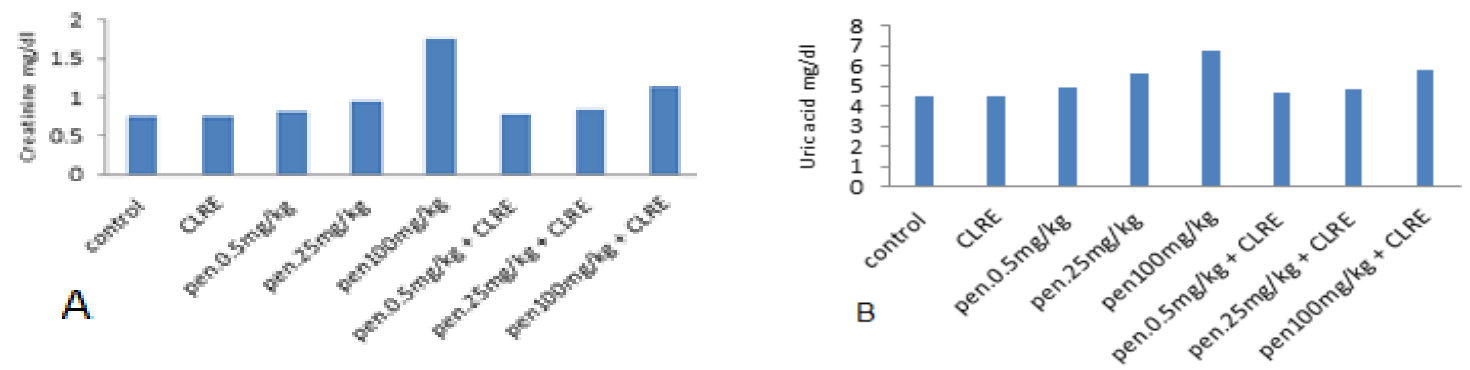

Fig.1: Effect of exposure to penconazole (Pen.) treatments on serum creatinine (A) and uric acid (B) of rat in the absence and presence of CLRE. Data are expressed as mean \pm S.E.M of 6 rats.

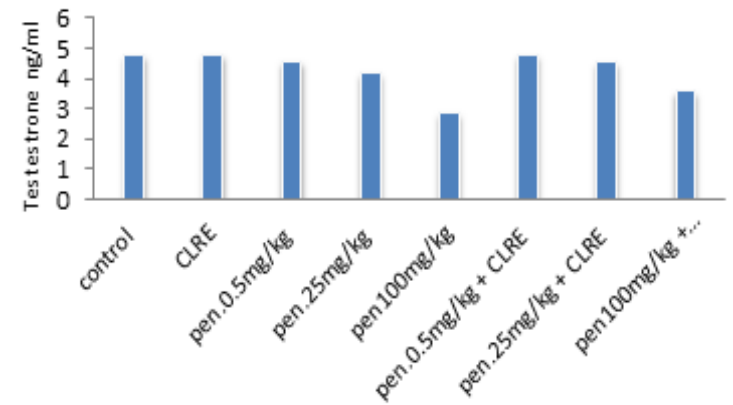

Fig. 2: Effect of exposure to penconazole treatments on serum testestrone of rat in the absence and presence of CLRE. Data are expressed as mean \pm S.E.M of 6 rats.

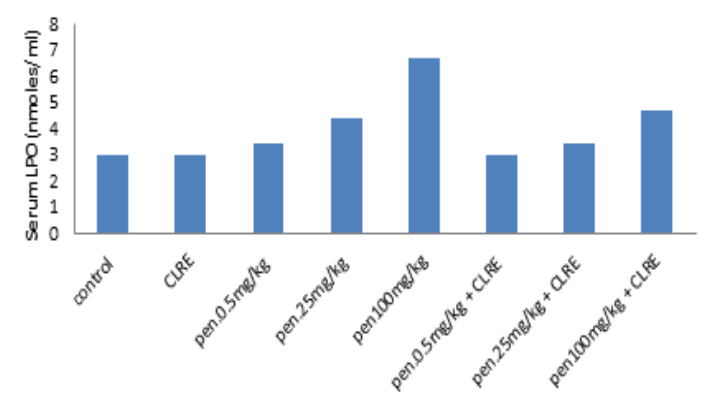

Fig. 3: Effect of exposure to penconazole treatments on Serum lipid peroxidation (LPO)) of rat in the absence and presence of CLRE. Data are expressed as mean \pm S.E.M of 6 rats.

Table 3: Effect of penconazole treatments on antioxidant enzymes of liver and kidney male rats and the ameliorative role of $C$. Longa Rhizome Ethanolic Extract (CLRE).

\begin{tabular}{|c|c|c|c|c|c|c|}
\hline \multirow{2}{*}{ Treatment } & \multicolumn{2}{|c|}{ SOD U/mg protien } & \multicolumn{2}{|c|}{ CAT (nmoles/min/mg protein) } & \multicolumn{2}{|c|}{ GPx (nmoles/min/mg protein) } \\
\hline & liver & kidney & Liver & kidney & liver & Kidney \\
\hline Untreated Control & $11.94 \pm .04^{\mathrm{a}}$ & $18.98 \pm .03^{\mathrm{a}}$ & $400.02 \pm .30^{\mathrm{a}}$ & $221.06 \pm .05^{\mathrm{a}}$ & $5.01 \pm .03^{\mathrm{a}}$ & $4.39 \pm .01^{\mathrm{a}}$ \\
\hline CLRE & $12.08 \pm .13^{\mathrm{a}}$ & $19.04 \pm .02^{\mathrm{a}}$ & $399.50 \pm .25^{\mathrm{a}}$ & $221.13 \pm 0.02^{\mathrm{a}}$ & $5.05 \pm .03^{\mathrm{a}}$ & $4.40 \pm .02^{\mathrm{a}}$ \\
\hline Pen. $0.5 \mathrm{mg} / \mathrm{kg}$ & $10.94 \pm .03^{\mathrm{d}}$ & $18.01 \pm .05^{\mathrm{c}}$ & $365.92 \pm .29 \mathrm{c}$ & $181.65 \pm .16^{\mathrm{d}}$ & $4.80 \pm .01^{\mathrm{b}}$ & $4.21 \pm .01^{\mathrm{c}}$ \\
\hline Pen $.25 \mathrm{mg} / \mathrm{kg}$ & $9.93 \pm .02^{\mathrm{e}}$ & $15.40 \pm .04^{\mathrm{e}}$ & $302.05 \pm 0.04^{\mathrm{f}}$ & $139.89 \pm .06^{\mathrm{f}}$ & $4.41 \pm .01^{\mathrm{c}}$ & $3.67 \pm .01^{\mathrm{e}}$ \\
\hline Pen. $100 \mathrm{mg} / \mathrm{kg}$ & $8.69 \pm .03^{\mathrm{f}}$ & $12.34 \pm .06^{\mathrm{f}}$ & $202.15 \pm .29^{g}$ & $108.87 \pm .09^{g}$ & $3.18 \pm .02^{\mathrm{e}}$ & $2.90 \pm .01^{\mathrm{f}}$ \\
\hline Pen. $0.5 \mathrm{mg} / \mathrm{kg}$ + CLRE & $11.77 \pm .02^{\mathrm{b}}$ & $18.71 \pm .04^{\mathrm{b}}$ & $391.28 \pm .25^{\mathrm{b}}$ & $218.78 \pm .13^{\mathrm{b}}$ & $4.99 \pm .03^{\mathrm{a}}$ & $4.37 \pm .01^{\mathrm{a}}$ \\
\hline Pen $.25 \mathrm{mg} / \mathrm{kg}+$ CLRE & $11.49 \pm .05^{\mathrm{c}}$ & $17.97 \pm .03^{c}$ & $343.99 \pm .25^{\mathrm{d}}$ & $192.84 \pm .06^{\mathrm{c}}$ & $4.77 \pm .03^{\mathrm{b}}$ & $4.29 \pm .01^{\mathrm{b}}$ \\
\hline Pen. $100 \mathrm{mg} / \mathrm{kg}+$ CLRE & $11.01 \pm .04^{\mathrm{d}}$ & $15.91 \pm .04^{\mathrm{d}}$ & $307.61 \pm .19^{\mathrm{e}}$ & $166.06 \pm 0.05^{\mathrm{e}}$ & $4.18 \pm .01^{\mathrm{d}}$ & $3.86 \pm .04^{\mathrm{d}}$ \\
\hline
\end{tabular}

Each value is a mean of 6 rats \pm S.E.M; $a, b, c, d$ values are not sharing superscripts letters $(a, b, c, d)$ differ significantly at $p<0.05$.

\subsection{Histopathological examination}

The representative pictures of histopathological examination in the liver, kidney and testis tissues are shown in Fig.4, 5 \& 6. The semi-quantitative histological scoring of liver, kidney and testis damage was presented in Table 4. Liver sections from the control group rats showed normal hepatic cytoarchitecture (Fig. 4A). They formed of hepatocytes radiating from central vein to the periphery of the lobules. Liver lobules of penconazole dosages at $0.5,25$ and $100 \mathrm{mg} / \mathrm{kg}$ b.w. showed focal hepatic necrosis, congestion of central vein and focal hepatic necrosis associated with inflammatory cells infiltration and portal infiltration with inflammatory cells and hydropic degeneration of hepatocytes, consequently (Figs. 4; C, E\&G). On the other side, Histopathological examination of liver of CLRE extract to penconazole treated groups exhibited that hepatocytes was completely recovered at the low penconazole dose $(0.5 \mathrm{mg} / \mathrm{kg}$ b.w). However, partial recovery was noticed at 25 , and $100 \mathrm{mg} / \mathrm{kg}$ b.w. Where, the severity of the above cited histological abnormalities ranged from moderate to severe degree. Kidney sections from the control group rats and CLRE extracttreated rats showed the normal histological structure of renal parenchyma (Fig. 5A). However, abnormalities in kidney of penconazole dosages $(0.5,25$, and $100 \mathrm{mg} / \mathrm{kg}$ b.w) treated rats were detected in cystic dilatation of renal tubules with intraluminal eosinophilic protein cast, vacuolation of epithelial lining renal tubules and focal necrosis of renal tubules associated with inflammatory cells infiltration, respectively (Figs. 6;C, E\&G). It was observed that the co-administration of the turmeric extract 
with penconazole showed different degrees of improvement in their histological structure in comparison to the treated groups Testicular sections from the control group rats, CLRE extract and penconazole groups -treated rats showed the necrobiotic changes of seminiferous tubules were recorded; its degree of damage ranged from apparently normal-looking seminiferous tubules to degenerated seminiferous epithelium lined by single layer of cells, consisting of sertoli cells and few spermatogonia (Figs. 6C, E\&G). Penconazole dosages $(0.5,25 \mathrm{mg} / \mathrm{kg}$ b.w $)$ treated rats showed marked degeneration and necrosis of spermatogoneal cells lining

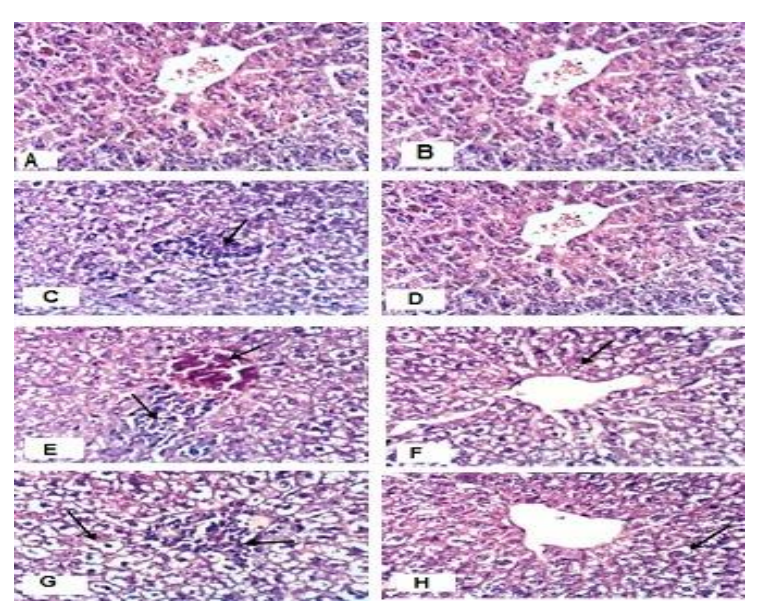

Fig. 4: Histopathological examination of rat liver. (A,B) showing apparent normal hepatocytes in control and CLRE, $0.5 \mathrm{mg} / \mathrm{kg}$ penconazole-treated animal liver (C) showing focal hepatic necrosis associated with inflammatory cells infiltration, and plus CLRE (D) showing apparent normal hepatocytes. $25 \mathrm{mg} / \mathrm{kg}$ penconazole -treated rat liver (E) showing congestion of central vein and focal hepatic necrosis associated with inflammatory cells infiltration and plus CLRE $(\mathrm{F})$ showing hydropic degeneration of hepatocytes. $100 \mathrm{mg} / \mathrm{kg}$ penconazole-treated rat liver $(\mathrm{G})$ portal infiltration with inflammatory cells and hydropic degeneration of hepatocytes and plus CLRE (H) showing hydropic degeneration of hepatocytes. Specimens stained with hematoxylin and eosin (H \& E X 400). seminiferous tubules with formation of spermatid giant cells, and congestion of testicular blood vessel. However, dose of $100 \mathrm{mg} / \mathrm{kg}$ b.w showed marked degeneration and necrosis of spermatogoneal cells lining seminiferous tubules and congestion of testicular blood vessel. On the other hand, the co-administration of the turmeric extract with penconazole showed marked improvement in their histological structure in comparison to the treated groups (3, 4 and 5) alone. Where, histological structure was more or less similar to control group.

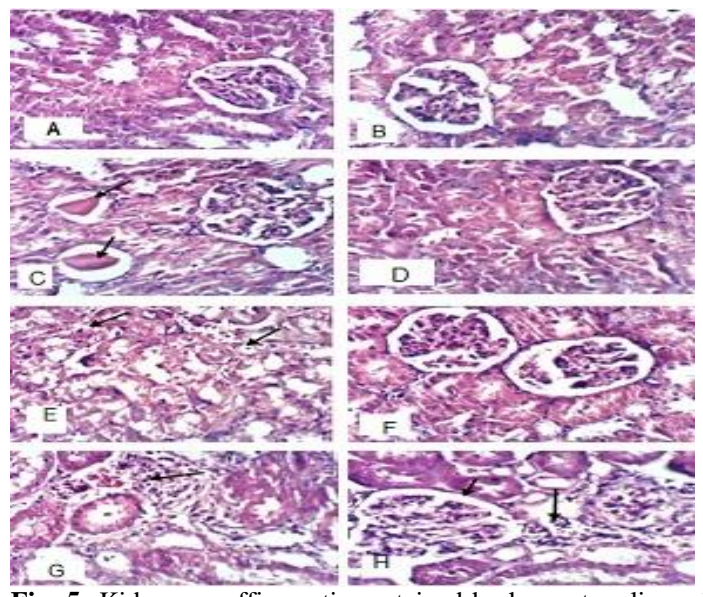

Fig. 5: Kidney paraffin sections stained by haematoxylin and eosin (H\&E $X$ 400) for histopathological changes. Control group and CLRE (A,B) showing the normal histological structure of renal parenchyma, $0.5 \mathrm{mg} / \mathrm{kg}$ penconazole-treated animal kidney(C) showing cystic dilatation of renal tubules with intraluminal eosinophilic protein cast and plus CLRE (D) showing no histopathological changes, $25 \mathrm{mg} / \mathrm{kg}$ penconazole -treated rat(E) showing vacuolation of epithelial lining renal tubules and plus CLRE (F) showing no histopathological changes, $100 \mathrm{mg} / \mathrm{kg}$ penconazoletreated rat $(\mathrm{G})$ showing focal necrosis of renal tubules associated with inflammatory cells infiltration and plus CLRE $(\mathrm{H})$ showing slight hypertrophy of glomerular tuft and few interstitial inflammatory cells infiltration.

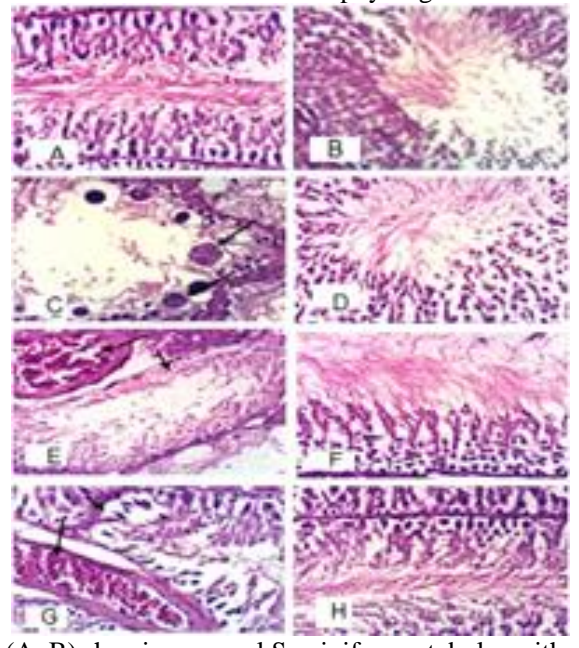

Fig. 6: Histopathological examination of rat testes. (A, B) showing normal Seminiferous tubules with normal spermatogoneal cells and complete spermatogenesis with sperm production in control and CLRE, $0.5 \mathrm{Mg} / \mathrm{Kg}$ penconazole-treated animal testes (C) showing marked degeneration and necrosis of spermatogoneal cells lining seminiferous tubules with formation of spermatid giant sells and plus CLRE (D) showing no histopathological changes, 25 $\mathrm{Mg} / \mathrm{Kg}$ penconazole -teated rat $(\mathrm{E})$, showing marked degeneration and necrosis of spermatogoneal cells lining seminiferous tubules and congestion of testicular blood vessel and plus CLRE (F) showing no histopathological changes, $100 \mathrm{Mg} / \mathrm{Kg}$ penconazole -Treated Rat Testes (G) Marked Degeneration and Necrosis of Spermatogoneal Cells Lining Seminiferous Tubules and Congestion of Testicular Blood Vessel and Plus CLRE (H) Showing No Histopathological Changes Specimens Stained with Hematoxylin and Eosin (H \& E X 400). 
Table 4: Semi-quantitative scoring of architectural damage on histopathological examination of the liver, kidney and testes rat in different treatment groups.

\begin{tabular}{|c|c|c|c|c|c|c|c|c|}
\hline Histopathological lesions & control & CLRE & $\begin{array}{c}\text { Pen. } \\
0.5 \mathrm{mg} / \mathrm{kg} \\
\end{array}$ & $\begin{array}{c}\text { Pen. } \\
25 \mathrm{mg} / \mathrm{kg}\end{array}$ & $\begin{array}{c}\text { Pen. } \\
100 \mathrm{mg} / \mathrm{kg} \\
\end{array}$ & $\begin{array}{c}\text { Pen. } \\
0.5+\text { CLRE } \\
\end{array}$ & $\begin{array}{c}\text { Pen. } \\
25+\text { CLRE } \\
\end{array}$ & $\begin{array}{c}\text { Pen. } \\
100+\text { CLRE }\end{array}$ \\
\hline \multicolumn{9}{|c|}{ Liver } \\
\hline $\begin{array}{l}\text { Hydropic degeneration of } \\
\text { hepatocytes }\end{array}$ & - & - & ++ & ++ & +++ & + & - & ++ \\
\hline Focal hepatic necrosis & - & - & ++ & +++ & +++ & - & - & - \\
\hline $\begin{array}{l}\text { Portal infiltration with } \\
\text { inflammatory cells }\end{array}$ & - & - & - & + & + & - & - & - \\
\hline Hyperplasia of bile duct & - & - & + & ++ & ++ & - & - & - \\
\hline Fibroplasia in portal triad & - & - & + & + & ++ & - & - & - \\
\hline $\begin{array}{l}\text { Congestion of central vein } \\
\text { or sinusoids }\end{array}$ & - & - & - & - & ++ & - & - & + \\
\hline \multicolumn{9}{|c|}{ Kidneys } \\
\hline $\begin{array}{l}\text { Congestion of renal } \\
\text { blood vessels }\end{array}$ & - & - & ++ & ++ & +++ & - & - & + \\
\hline $\begin{array}{l}\text { Vacuolation of renal } \\
\text { tubular epithelium }\end{array}$ & - & - & + & ++ & +++ & - & - & - \\
\hline $\begin{array}{l}\text { Protein cast in renal } \\
\text { tubules }\end{array}$ & - & - & - & + & ++ & - & - & + \\
\hline Focal tubular necrosis & - & - & - & - & ++ & - & - & - \\
\hline Interstitial nephritis & - & - & - & - & + & - & - & + \\
\hline \multicolumn{9}{|c|}{ Testes } \\
\hline $\begin{array}{l}\text { Degeneration and necro- } \\
\text { sis of spermatogoneal } \\
\text { cells }\end{array}$ & - & - & ++ & +++ & +++ & - & - & + \\
\hline Spermatid giant cells & - & - & - & - & +++ & - & - & - \\
\hline $\begin{array}{l}\text { Congestion of testicular } \\
\text { blood vessels }\end{array}$ & - & - & + & ++ & ++ & - & - & + \\
\hline
\end{tabular}

\section{Discussion}

Penconazole is an agricultural fungicide, which is used by foliar application to control a wide range of diseases in fruits and vegetables. As a result of their wide use, fungicide residues were found to contaminate crops and water resources (Pan \&Ho 2004 \& Wang et al. 2005). The scope of this study is to investigate the sub acute exposure of the penconazole fungicide on histopathology and function of liver, kidney and testes on albino rats and to examine the prophylactic effect of ethanolic extract of Curcuma longa against penconazole induced toxicity. In toxicological studies, weights of body and relative organ are important criteria for evaluation of organ toxicity. The results showed that, the continuous exposure to penconazole at the doses of $0.5,25$ and $100 \mathrm{mg} / \mathrm{kg}$ b.w., orall feeding, for 28 days continuously, caused significant reductions in body weight and relative weights of the testes than control. However, significant increment in the relative liver and kidney weights were detected compared to the control. The reduction in body weight may be attributed to the combined action of cholinergic and oxidative stress(Grance et al. 2008, Dirican \& Kalender 2011, Saafi et al. 2011) and/or due to the overall increased degradation of lipids and proteins. Moreover, the noticeable increments in liver and kidney weights could be due to the relationship between both liver and kidney weights increase and various toxicological effects or the reduction in body weight gain of experimental animals. These results agreed with the findings of (El-Sharkawy \& El-Nisr 2013, Chaabane et al.2015). However, co-administration of CLRE extract treatments ameliorated body and liver weights of intoxicated rats.

Liver is the largest organ in the vertebrate body and is the major site of xenobiotic metabolism and excretion that plays a key role in the detoxification process. Therefore, any injury or impairment type of its function produces hepatotoxicity and causes health complications. Liver enzymes such as AST, ALT, ALP, $\gamma$-GT and LDH are the most commonly used biomarkers of liver injury. In the present work, the activities of these enzymes exhibited marked elevation indicting hepatocellular damage. The elevation in the activities of these enzymes could be due to some conditions including muscle damage, intestinal and hepatic injury and toxic hepatitis (Farkas et et al. 2004). Confirming with this interpretation (Alhazza 2007) displayed that, destruction of cells and damage of tissue caused elevated enzymes in liver as well as accumu- lation of triglycerides and release enzymes into the bloodstream caused emergence of necrosis in cells of liver tissue.

The liver is a major organ of protein synthesis. Therefore, any disease in liver can cause damage of hepatocytes with changes in protein and free amino acid metabolism leading to decrease synthesis and increase wasting via catabolism (Yousef et al. 2006, Wallace 2007, El- Shafey et al. 2011, Eidi et al. 2013). The decreased level of total proteins in serum due to treatedpenconazolerats reflect the severity of liver toxicity as reported by (Chaabane et al. 2015)

The treated- penconazole rats showed augmentation in serum glucose level which associated with a positive significant influencein daily water intake. This suggested that a longer exposure period of penconazole could probably induce diabetes. The obtained results are in line with the results of (Abdollahi et al .2004) who reported that, treated-malathion rat's stimulated glycogenolysis in several organs and of gluconeogenesis in liver, leading to the release of glucose into the blood.

The collective result supports the suggestion; treatment with turmeric extract could provide appropriate host to protect the hepatocytes from progressive damage. The increase of uric acid concentration is a demonstration of impaired kidney function since the organ primarily excretes urea in the urine. Elevated creatinine is correlated with an increased protein catabolism, as creatinine is the end product of protein catabolism. Obviously, our results revealed significant increases in serum uric acid and creatinine concentrations following the sub-acute penconazole administration compared to the control. Increasing serum uric acid and creatinine concentrations may be due to the reduction in glomerular filtration in the kidney and dysfunction of the kidney tubules (Walmsley \& White 1994). Similar findings were demonstrated by (Eissa\&Zidan 2010). The increase in creatinine due to penconazole administration was, also, correlated closely with the histopathological changes in the kidney as shown in figure (5).

Turmeric extracts have been reported to have positive effects as antimicrobial, anti-inflammatory, antioxidant and anticancer agents (Arora et al. 1971, Leela\&Shalini1991, Leela et al.1992). The hepato-protective effects of turmeric and curcumin might be due to the direct effect of antioxidant and free radical scavenging mechanisms and indirect effect to augment glutathione levels by aiding in hepatic detoxification. Furthermore, the hydro ethanolic extract of turmeric hinders the stimulation of human dendrite cells in answer to the inflammatory cytokines (Lantz et al. 2005). Ac- 
tive principle of turmeric extract ameliorated diabetic nephropathy in rats and the anti-oxidative mechanism being responsible for the nephro-protective action of curcumin, which might be potentially useful in some kidney diseases by preventing renal inflammation as reported by (Sharma et al. 2006). Turmeric extract was found to possess multiple therapeutic activities that block the cardiac, hepatic and renal toxicities induced by arsenic trioxide (Saxena et al. 2009) and had as a free radical scavenger activity. In this respect (Krup et al.2013) reported that, the ethanolic extract of Curcuma longa rhizomes showed a significant hepato-protective effect when orally administrated at 250 and $500 \mathrm{mg} / \mathrm{kg}$ b.w.

Exposure of experimental animals to pesticides is known to induce lipid peroxidation in various tissues, which leads to adverse biological effects (El-Demerdash et al. 2004). The inhibition activity on CAT, SOD and GPx and enhance of lipid peroxidation in treated- penconazolerats could be explained based on induction free radicals. Highly reactive oxygen metabolites, especially hydroxyl radicals, act on unsaturated fatty acids of phospholipid components of membranes to produce malondialdehyde, a LPO product. Under normal circumstances, the imbalance between production of oxygen free radicals (OFRs) and antioxidant defenses in the body is called oxidative stress, which has important health implications (Wei et al. 2006).

Phenolic compounds are powerful antioxidants, which defend the human body against free radicals. Usually, the deleterious effects of oxidative stress, result from the generation of free radicals, are counteracted by endogenous antioxidant enzymes such as CAT, SOD, and GPx. Hence, results from the current study suggest that, turmeric ethnolic extract could reduce liver, kidney and testes injury induced by penconazole. The mechanism by which this extract exerted its protective action could be due to wide range of bioactive compounds i.e. antioxidant activity including phenolics. The principle isolated of Curcuma longa Linn rhizome is active flavonoid curcuminoids, which is a mixture of curcumin (diferuloylmethane), monodexmethoxycurcumin and bisdesmethoxycurcumin. Curcumin represents up approximately $90 \%$ of the curcuminoids content in turmeric (Heath 2004, Sandur et al. 2007). Turmeric aqueous extract have $\mathrm{O}_{2}$ 'scavenging activity protected the cells from induced cell death. Also, it causes a marked decrease in malondialdehyde (MDA) and, significantly, elevated the antioxidant enzymes activity; glutathione peroxidase, and catalase (Koo et al. 2004 \& Jain et al. 2006). Turmericis consider being abundant in phenolic components such as curcuminoids that grab the antioxidant activity of turmeric curcuminoids avert the development of free radicals (Maizura et al. 2011).

Results indicated that, concentration of hormone testosterone in serum of the exposed penconazole rats, significantly, were lower than the control. The decrease in testosterone hormone concentration may be contributed to testicular hypo function. In addition; the obtained data showed a dose-dependent difference obtained in the most recorded parameters. The differences at $p<0.05$ where statistically significance dose $100 \mathrm{mg} / \mathrm{kg}$ b.w. was among toxic effects of penconazole on testes of exposed groups may be attributed to penconazole fungicides that mimic steroid hormones, and are called endocrine disruptive chemicals, because they alter the expression of endocrine-regulated gene (Perreault, 1997; Makame et al. 2004). Penconazole inhibits testosterone production (FAO/WHO, 1998). Penconazole was inhibited aromatase activity, decrease estrogens production and increase androgens availability (Trosken et al. 2004). These results are in agreement with (El-Sharkawy\& El-Nisr 2013). A testes was the organ of choice as it is used as a sensitive indicator to male reproductive toxicity. A role of penconazole in endocrine disrupting mediated effects and strongly suggesting a possible mode of action in thyroid carcinogenesis (Perdichizzi et al. 2014).

\section{Conclusion}

In summary, we conclude that penconazole exposure leads to hepato-nephrotoxicity and fertility toxicity in adult rats as revealed by an increase of lipid peroxidation and an alteration of antioxidant status, associated with liver and kidney histological disorders. Penconazole inhibited testosterone production. Restriction in the use of penconazole as a fungicide to protect crops should be taken in consideration. Prevention of penconazole exposure to farm animals and regular monitoring of residues in the environment must be applied. The present results demonstrated that the tumeric extract protects the liver and kidney tissues against toxic effects of penconazole. On the basis of this study, the use of tumeric rhizomes as a functional food or as a nutraceutical product could be a useful approach to protect individuals who are regularly exposed to penconazole.

Our findings supported that the use of tumeric extract may therefore be more effective for clinical purposes with antioxidant properties. However, further investigations will be done to elucidate the mechanism of protection and potential usefulness of these plant extract as a source of protective agents against drugs or xenobiotics toxicity in clinical trials.

\section{Acknowledgement}

The authors are grateful of Prof. Dr. Kawkab Abd El-Aziz Ahmed, Professor of Pathology, Faculty of Veterinary Medicine, Cairo University for interpreting the histopathological sections.

\section{References}

[1] Abdollahi M, Ranjbar A, Shadnia S, NikfarS\&RezaieA (2004) Pesticides and oxidative stress: a review Med. Sci. Monitor 10: 141147.

[2] Aebi H (1984) Catalase in vitro. Methods Enzymology 105: 121126. http://dx.doi.org/10.1016/S0076-6879(84)05016-3.

[3] Alhazza IM (2007) Antioxidant and hypolipidemic effects of olive oil in normal and diabetic male rats. Saudi Journal of Biological Sciences 14: 69-74

[4] Arora RB, BasuN, Kapoor V\&Jain AP (1971) Anti-inflammatory studies on Curcuma longa L. Ind. Med. Res 59: 1285-1289.

[5] BancroftGD, Stevens A\&Turner DR (1996) Theory and practice of technique. 4th ed. New York: Churchill Livingston.

[6] Barham D\&TrinderP (1972) Analyst 97: 142 http://dx.doi.org/10.1039/an9729700142.

[7] Basler W, KomarekJ, ZakF\&SkorpilV (1984) CGA 71818: 28-day oral cumulative toxicity study in rats. Unpublished final report, GU project No. 820822 dated 28 June 1984 from Ciba-Geigy, Basle, Switzerland. Submitted to WHO by Ciba-Geigy Ltd., Basle, Switzerland.

[8] Chaabanea M, SoudaniN, BenjeddouK, TurkiA, MakniMF, BoudawaraT, ZeghalN\&GhorbelRE (2015) the protective potential of Nitrariaretusa on penconazole-induced hepatic injury in adult rats. Toxicological \& Environmental Chemistry. ISSN: 0277-2248 (Print) 1029-0486 (Online). Journal homepage.http://www.tandfonline.com/loi/gtec 20.

[9] DiricanEK\&KalenderY (2011) Dichlorvos-induced testicular toxicity in male rats and the protective role of vitamins $\mathrm{C}$ and E. Exp. ToxicolPathol. http://dx.doi.org/10.1016/j.etp.2011.03.002.

[10] EFSA, Scientific Report (2008) Conclusion on the peer review of penconazole175: 1-104.

[11] Eidi A, MoghadamJZ, MortazaviP, RezazadehS\&OlamafarS (2013) Hepatoprotective effects of Juglansregia extract against CCl4induced oxidative damage in rats. Pharm. Biol 51(5): 558-65. http://dx.doi.org/10.3109/13880209.2012.749920.

[12] Eissa FI\&ZidanNA (2010) Haematological, biochemical and histopathological alterations induced by abamectin and Bacillus thuringiensisin male albino rats. Acta Biol. Hung 61 (1): 33-44 http://dx.doi.org/10.1556/ABiol.61.2010.1.4.

[13] El- ShafeyAM,SeliemME

El-MahroukyF, GabrWM\&KandilRA(2011) Some physiological and biochemical effects of Oshar extract and abamectin biocide on male albino rats. J. Am. Sci7 (12): 254-261.

[14] El-Demerdash FM, Yousef IM,KedwanyFS\&Baghdadi HH (2004) "Cadmium Induced Changes in Lipid Peroxidation, Blood Hematology, Biochemical Parameters and Serum Quality of Male Rats: Protective Role of Vitamin E and b-Carotene." Food and Chemical Toxicology 42: 1563-1571. http://dx.doi.org/10.1016/j.fct.2004.05.001 
[15] El-Sharkawy EE\& El-NisrNA (2013) Testicular dysfunction induced by penconazole fungicide on male albino rats. Comp. Clin Pathol22:475- 480. http://dx.doi.org/10.1007/s00580-012-1435-4.

[16] EuropeanChemicals Agency (2012) ECHA/RAC/CLH-O 0000002679-61- 01/A1.BACKGROUND DOCUMENT TO RAC OPINION ON PENCONAZOLE.

[17] FAO/WHO. (1991) Pesticide residues in food: 1991 evaluation. Part 1, paper 113/1. Residues. FAO plant production and protection.

[18] FAO/WHO. (1998) The WHO recommended classification of pesticides by hazard and guidelines to classification 1997-1998 (WHO/PCS/ 90.1). Available from the international program on chemical safety, World Health Organization, Geneva, Switzerland.

[19] Farkaset J, Farkas P\& Hyde D (2004) Liver and gastroenterology tests, ini basic skills in interpreting laboratory data. Mary Lee 3rd Edition. American Society of Health System Pharmacists, Bethesda, Maryland, USA 330-336.

[20] Gornall AC, BardawillCJ\& David MM (1949) Determination of serum protein by means of biuret reaction. J. Biol. Chem 177: 751756.

[21] Grance SR, Teixeira MA, LeiteRS , GuimaresEB , de SiqueiraJM\&de Oliveira FiliuWF(2008)Baccharistrimera: effect on hematological and biochemical parameters and hepato-renal evaluation in pregnant rats. J. Ethnopharmacol 117: 28-33. http://dx.doi.org/10.1016/j.jep.2007.12.020

[22] Heath DD, KhwajaF\& RockCL (2004) Curcumin content of turmeric and curry powders. FASEBJ.18:A125.

[23] Jain SK, Rains J\& JonesK (2006) Effect of Curcumin on protein glycosylation, lipid peroxidation, and oxygen radical generation in human red blood cells exposed to high glucose levels. Free radical Biol. and Med 41: 92-96. http://dx.doi.org/10.1016/j.freeradbiomed.2006.03.008.

[24] Kodjio N, AtsafackSS, NjatengGS, SokoudjouJB, Kuiate1J\&GatsingD (2016) Antioxidant Effect of Aqueous Extract of Curcuma longa Rhizomes (Zingiberaceae) in the Typhoid Fever Induced in Wistar Rats Model.Journal of Advances in Medical and Pharmaceutical Sciences 7(3): 1-13. (ISSN: 2394-1111).

[25] Koo BS, Lee WC, Chung KH, KoJH\& KimCH (2004) a water extract of CL. (Zingiberaceae) rescues PC12 cell death caused by pyrogallol on hypoxia/reoxygenation and attenuates hydrogen peroxide induced injury in PC12 cells. Life Sci 75(19): 2363-2375. http://dx.doi.org/10.1016/j.lfs.2004.07.003.

[26] Krup V, Prakash LH\&HariniA (2013) Pharmacological Activities of Turmeric (Curcuma longa linn): A Review. J. HomeopAyurv Med 2: 133. http://dx.doi.org/10.4172/2167-1206.1000133.

[27] Lantz RC, ChenGJ, Solyom AM, JoladSD\&TimmermannBN (2005) the effect of turmeric extracts on inflammatory mediator production. Phytomedicine 12: http://dx.doi.org/10.1016/j.phymed.2003.12.011.

[28] Larsen K (1972) Clin. Acta 41, 209. http://dx.doi.org/10.1016/0009-8981(72)90513-X.

[29] Leela S\&ShaliniV K (1991) DNA damage by smoke: Protection by Turmeric and other inhibitors of ROS. Free RadicBiol Med 11: 277-283. http://dx.doi.org/10.1016/0891-5849(91)90124-L.

[30] Leela S, ShaliniVK\&ShylajaM (1992) Turmerin: A water soluble antioxidant peptide from Turmeric (Curcuma longa). Arch BiochemBiophys 292: 617- 623. http://dx.doi.org/10.1016/00039861(92)90040-4.

[31] Lepesheva GI, Virus C\& WatermanMR (2003) Conservation in the CYP51 family. Role of the B' helix/BC loop and helices F and G in enzymatic function Biochemistry42: 9091-9101.

[32] Maizura M, AminahA\& Wan-Aida WM (2011) Total phenolic content and antioxidant activity of kesum (Polygonum minus), ginger (Zingiberofficinale) and turmeric (Curcuma longa) extract. Int. Food Res. J 18: 529-534.

[33] Makame T, HokansonR, ChowdharyR\&BusbeaD (2004)Alteredgene expression in human cells induced by the agricultured chemical enables. ToxicolInd Health 20(6-10):89-102. http://dx.doi.org/10.1191/0748233704th198oa

[34] Marquardt H\& SchaferS (2004) Vol. 1, pp. 1348 WissenschaftlicheVerlagsgesellschaftmbH, Stuttgart.

[35] McLean KJ, Marshall KR, Richmond A, Hunter IS, Fowler K, Kieser T, Gurcha SS, BesraGS\& MunroAW (2002)Azole antifungals are potent inhibitors of cytochrome $\mathrm{P} 450$ mono-oxygenases and bacterial growth in mycobacteria and streptomycetes Microbiology148: 2937-2949

[36] Nishikimi M, Rao NA\&YogK (1972)Colormetric determination of superoxide dismutase activity.Biochem.Biophys. Res. Commun 46: 849-851. http://dx.doi.org/10.1016/S0006-291X(72)80218-3.
[37] Paglia DE\& Valentine WN (1987) Studies on the quantitative and qualitative characterization of glutathione peroxidase. J. Lab. Clin. Med 70: 158-165.

[38] Pan JH\& HoWH (2004) Determination of fungicide in water using liquid phase micro extraction and gas chromatography with electron capture detection. Anal ChimActa 527(1):61-67. http://dx.doi.org/10.1016/j.aca.2004.08.016

[39] Perdichizzi S, Mascolo MG, Silingardi P, Morandi E, Rotondo F, Guerrini A, Prete L, Vaccari M\&ColacciA (2014)Cancer-related genes transcriptionally induced by the fungicide penconazole.Toxicol in Vitro 28(1):125-130 http://dx.doi.org/10.1016/j.tiv.2013.06.006

[40] Perreault SD (1997) the mature spermatozoa as a target for reproductive toxicants. In: Bokelheide K, Chapin RE, Hoyer PB, Craig H (eds) Comprehensive toxicology: reproductive and endocrine toxicology, vol 10. Pergamon, New York, pp 165-191.

[41] Podust LM, PoulosTL \& WatermanMR (2001) Crystal structure of cytochrome P450 14alpha -sterol demethylase (CYP51) from Mycobacterium tuberculosis in complex with azole inhibitors ProcNatl. Acad. Sci. U S A, 98: 3068-3073. http://dx.doi.org/10.1073/pnas.061562898.

[42] Reitman S\& FrankelSA (1957) Colorimetric method for the determination of serum glutamic oxalacetic and glutamic pyruvic transaminases. Am. J. Clin. Pathol28: 56-63 http://dx.doi.org/10.1093/ajcp/28.1.56.

[43] SaafiEB, LouediM, ElfekiA, ZakhamaA, NajjarMF\&HammamiaM (2011) Protective effect of date palm fruit extracts (Phoenix dactylifera L.) on dimethoate induced-oxidative stress in rat liver. ExpToxicolPathol63: 433-441.

[44] SandurSKPandey, MK, Sung B, Ahn KS, Murakami A, Sethi G, Limtrakul P, BadmaevV\& Aggarwal BB (2007) Curcumin, demethoxycurcumin, bisdemethoxycurcumin, tetrahydrocurcumin and turmerones differentially regulate anti-inflammatory and antiproliferative responses through a ROS-independent mechanism. Carcinogenesis 28: http://dx.doi.org/10.1093/carcin/bgm123.

[45] SAS, (2013) Statistical Analysis System. In SAS User's Guide: Statistics, version 9.2, SAS Inst., Inc.: Cary, NC 27513-2414 USA

[46] Satoh K (1978) Serum lipid peroxide in cerebrovascular disorders determined by a new colorimetric method. ClinicaChimicaActa 15(90): 37-43

[47] SaxenaPN, Anand S, SaxenaN\& Bajaj P (2009) Effect of arsenic trioxide on renal functions and its modulation by Curcuma aromaticaleaf extract in albino rat. J. Environ. Biol 30:527-531.

[48] Sharma S, Kulkarni SK\& Chopra K (2006) Curcumin, the active principle of turmeric (Curcuman longa), ameliorates diabetic nephropathy in rats. Clin. Exp. Pharmacol. Physiol 33: 940-945. http://dx.doi.org/10.1111/j.1440-1681.2006.04468.x.

[49] Sun G, Thai SF, Tully DB, Lambert GR, Gotez AK, Wolf DC, Dix DJ\&VesnowS (2005) Propiconazole induced cytochrome P450 gene expression and enzymes activities in rat and mouse liver. Tox$\begin{array}{lll}\text { icol } \quad \text { Lett } & \text { 155(2):277-287. }\end{array}$ http://dx.doi.org/10.1016/j.toxlet.2004.10.006

[50] Tietz NW (1995) Clinical Guide to laboratory Tests. 3rd ed. Philadelphia: WB Saunders 268-273.

[51] Trosken EE, Scholz K, LutzRW, Volkel W, ZarnJA\& Lutz WK (2004) Comparative assessment of the inhibition of recombinant human CYP19 (aromatase) by azoles used in agriculture and as drugs for humans. Endocr. Res 30: 387-394. http://dx.doi.org/10.1081/ERC-200035093.

[52] Vassault A (1983) Lactate dehydrogenase. UV-method with pyruvate and NADH. In: Bergmeyer J, Grabl M, eds. Methods of enzymatic analysis. Florida: Verlag-Chemie, Deer-ield Beach 119. 126.

[53] Wallace AH (2007) Principles and Methods of Toxicology. Healthcare USA, Inc., New York, 5th ed., 369-453.

[54] Walmsley RN\& White GH (1994) A Guide to Diagnostic Clini $\neg$ cal Chemistry. 3rd ed., Blackwell Publication, London, UK, 543 pp.

[55] Wang P, Jiang S, Liu D, Wang PI \& Zhou Z (2005) Direct enantiomeric resolutions of chiral triazole pesticides by high-performance liquid chromatography. J BiochemBiophys Meth 62(3):219-230. http://dx.doi.org/10.1016/j.jbbm.2004.11.007.

[56] WeiQY, Chen WF, Zhou B, Yang L\& Liu ZL (2006) Inhibition of lipid peroxidation and protein oxidation in rat liver mitochondria by curcumin and its analogues. BiochimicaEtBiophysica 1760: 70-77. http://dx.doi.org/10.1016/j.bbagen.2005.09.008.

[57] Whitfield JB, Moss DW, Neale G, Orme M\& Breckenridge A (1973) J. Brit. Med 1:136. 
[58] Yoshida, Y. (1988) Cytochrome P450 of fungi: primary target for azole antifungal agents Curr. Top. Med. Mycol2: 388-418. http://dx.doi.org/10.1007/978-1-4612-3730-3_11.

[59] Young DS, PestanerLC\&GibbermanV (1975) Effect of drug on clinical laboratory tests. ClinlChem 21: D431-2.

[60] Yousef MI, AwadIT\& Mohamed EH (2006) Deltamethrin-induced oxidative damage and biochemical alterations in rat and its attenuation by Vitamin E. Toxicology 227(3):240-247. http://dx.doi.org/10.1016/j.tox.2006.08.008.

[61] Zarn JA, BruschweilerBJ\&SchlatterJR (2003) Azole fungicides affect Mammalian steroidogenesis by inhibiting sterol 14 alphademethylase and aromatase. Environ. Health Perspect111:255-262. http://dx.doi.org/10.1289/ehp.5785.

[62] Zhang Q, Zhang J, Shen J, Silva A, Dennis DA\& Barrow CJ (2006) A simple 96-well microplate method for estimation of total polyphenol content in seaweeds. J. Appl. Phycol 18(3):445-450. http://dx.doi.org/10.1007/s10811-006-9048-4. 